\title{
Careers in Science and Grant Administration: View from the National Institutes of Health
}

\author{
Marion Zatz ${ }^{1}$ and Sherry Dupere ${ }^{2}$ \\ ${ }^{1}$ National Institute of General Medical Sciences, National Institutes of Health, Bethesda, Maryland 20892 \\ ${ }^{2}$ Eunice Kennedy Shriver National Institute of Child Health and Human Development, National Institutes of \\ Health, Bethesda, Maryland 20892 \\ Correspondence: marionzatz@gmail.com; duperes@mail.nih.gov
}

\begin{abstract}
Scientist administrators at the National Institutes of Health fall into two categories: program officers and scientific review officers. Program officers provide advice to applicants and grantees, make funding recommendations, oversee grantees' research progress, and facilitate research opportunities in emerging areas of science. Scientific review officers oversee all aspects of the initial (peer) review of grant applications.
\end{abstract}

\begin{abstract}
$A^{s}$ scientists progress through their research Acareers, they must think about how they can obtain funding to support their research. They can of course observe their mentors' efforts to apply for grants but often do not have a clear idea of what happens at the other end, that is, how grant applications are reviewed and how funding decisions are made. They may need someone who can provide advice, answer questions, and guide them through the maze of the grant application and funding process. A scientist administrator is that person. There are many funding agencies, both private and governmental, in the United States, and the nature of the job of a scientist administrator varies considerably with the funding agency. The National Institutes of Health (NIH) is the largest example, with an annual budget of nearly $\$ 32.3$ billion (https://report.nih.gov/NIH Data Book) supporting research and training grants to universities, medical schools, and their research institutions across the U.S. and around the world. As a result, there are thousands of scientist administra-
\end{abstract}

tor jobs located in the NIH Center for Scientific Review (CSR) and the 27 institutes and centers (ICs) that comprise the $\mathrm{NIH}$, and these individuals provide the merit review and funding recommendations of applications and the oversight of funded grants. Figure 1 shows the place of the $\mathrm{NIH}$ within the overall structure of government.

This chapter describes the job of an NIH health scientist administrator (HSA) and, more specifically, the roles of two types of scientist administrators, the program officer (PO) and the scientific review officer (SRO), who form the administrative team that serves the biomedical and behavioral research community. Potential principal investigators (PIs) often contact POs before submitting a grant application, seeking advice on a number of issues, including the appropriateness of a research project or training program for an institute's scientific mission or whether the application would be suited to a specific funding announcement. Trainees seeking fellowship support also may contact POs for advice on their applications.

Editors: Kaaren Janssen and Richard Sever

Additional Perspectives on Career Options for Biomedical Scientists available at www.cshperspectives.org

Copyright (C) 2018 Cold Spring Harbor Laboratory Press; all rights reserved; doi: 10.1101/cshperspect.a032847

Cite this article as Cold Spring Harb Perspect Biol 2018;10:a032847 
M. Zatz and S. Dupere

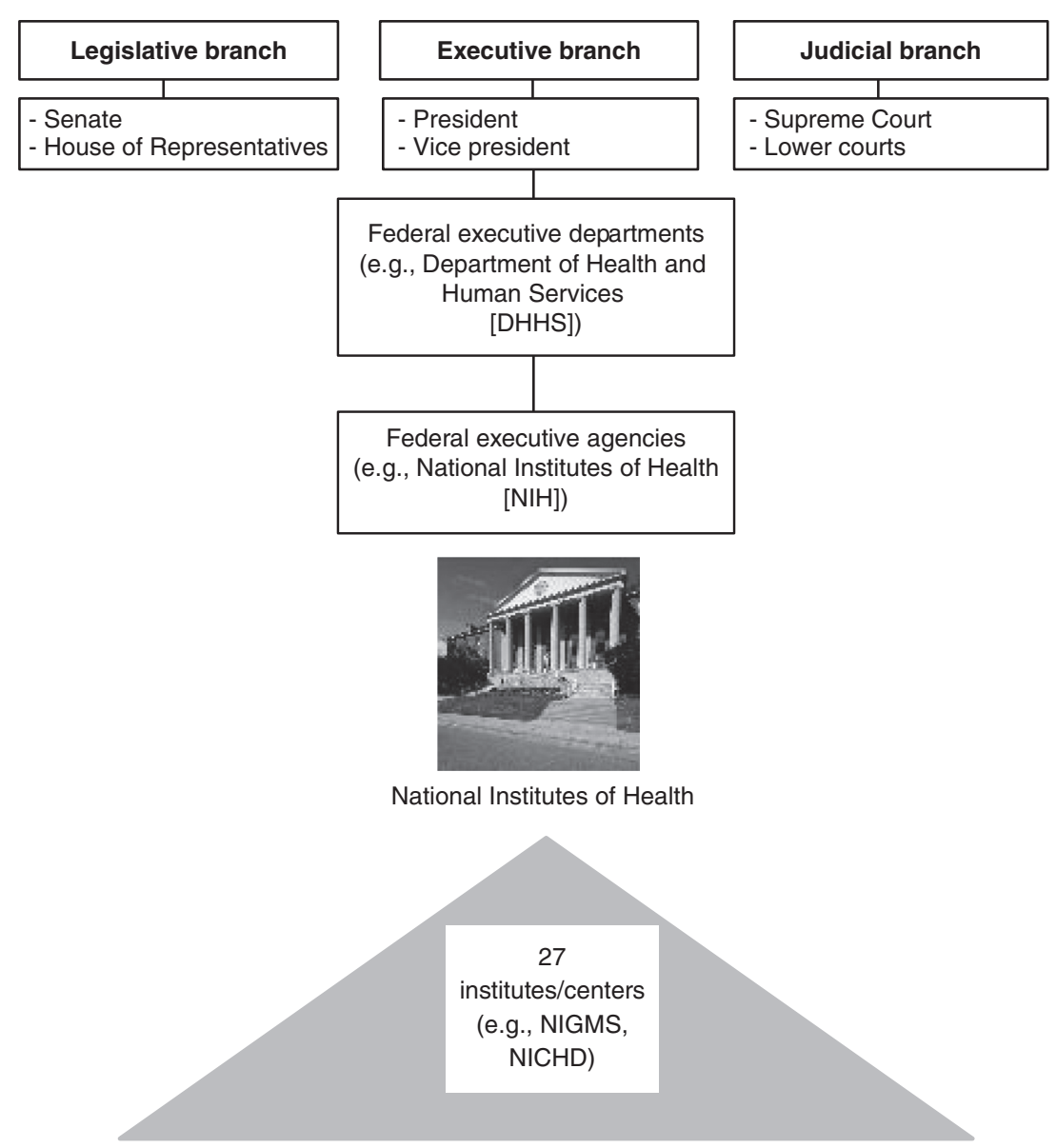

Figure 1. National Institutes of Health (NIH) as an agency of the Department of Health and Human Services within the executive branch of the United States government. The impact of all three federal branches on science and medicine is a rich aspect of careers in government. For example, the Health Scientist Administrator (HSA) may receive congressional inquiries from the legislative branch or, less commonly, become involved with a court of the judicial branch.

Once an application is received at the $\mathrm{NIH}$, the SRO is responsible for all aspects of peer review, including selecting scientists for scientific review group (study section) service, overseeing the review committee meeting, and generating the summary statements that capture the essence of the study section members' reviews. Once the initial scientific review is completed, responsibility shifts to the $\mathrm{PO}$, who advises applicants on their prospects for funding, makes funding recommendations, and, if the grant is funded, oversees the progress of the research. The PO also has responsibility for encouraging scientific opportunities, and both the PO and the SRO often provide advice on NIH policy.

Typically, there are three application submission deadlines a year and therefore three rounds of review and funding each fiscal year, so a PO or SRO may be juggling several different responsibilities simultaneously. These roles, described in greater detail below, are both scientifically and administratively challenging, but also highly rewarding and essential for the health of the country's biomedical and behavioral research enterprise. 
Although the current funding climate at the $\mathrm{NIH}$ is challenging, the NIH will continue to support the best research and the best research training of outstanding scientists, preparing them for independent careers in academia and the many other rewarding career options available. Although budget constraints may make it harder to make funding decisions and more difficult and time-consuming to advise applicants and grantees, the job of a scientist administrator becomes increasingly important in helping to sustain the enthusiasm and progress of the research and training enterprise.

\section{JOBS}

Positions for HSAs are found throughout the many institutes of the NIH. The organizational structure of one of these, the National Institute of Child Health and Human Development (NICHD), is represented in Figure 2.

\section{Program Officer}

The job of a PO will vary with the individual IC in which the position is located, although many of the basics are shared across the NIH. Most ICs have a research and training mission that is related to a specific disease or health focus, for example, the National Cancer Institute. There also is one institute, the National Institute of General Medical Sciences (NIGMS), whose mission is to support basic research and research training that is not tied to a particular disease or tissue/organ system. Because this reflects the NIGMS perspective of a PO's responsibilities, it is worth noting that NIGMS, just one of the 27 ICs, supports more than 3500 research grants and approximately 4300 trainees on fellowships and training grants.

\section{Advice}

Grant applicants may need advice at every step of the way, from whether their project is of interest to an IC's scientific mission or is responsive to a special initiative, to what the chances of funding are, or the next steps in revising and improving an application. An important part of a PO's job is to guide investigators and trainees through changing policies, practices, and budgets, providing as much information as possible along the way. Each fiscal year is different, and the job of a PO becomes even more important for providing accurate and timely information and advice.

\section{Funding Decisions}

This area varies considerably among ICs. In NIGMS, each PO is responsible for a defined scientific area in which he/she is particularly knowledgeable and has what is called a "portfolio" of applications and grants. The PO has an active role in making funding recommendations, starting with attendance at study section discussions, where the scientific merit of an application is discussed, and reading the summary statements that are generated for applications undergoing peer review. The next step is preparing for a second level of review by the NIGMS advisory council, during which council members may provide advice to applicant concerns and the relative merits of the scored applications; every application that is funded by the $\mathrm{NIH}$ must receive this second level of review by the relevant IC council. After the council meeting, POs discuss and recommend those applications that should be funded. This process is driven by research priorities and availability of funds (each IC receives its own budget appropriation from Congress) and the initial peer review evaluation. However, many other important factors are taken into consideration, including information gained from the study section discussion, council advice, the innovation of the scientific area, the applicant's status as a new or more established investigator, and the availability or lack of other support for the PI. POs also recommend the level of funding, making budget adjustments on a case-by-case basis.

\section{Oversight}

Once an application is funded and becomes part of a PO's portfolio, annual progress reports are read and evaluated for scientific advances and changes in direction that are still within 
M. Zatz and S. Dupere

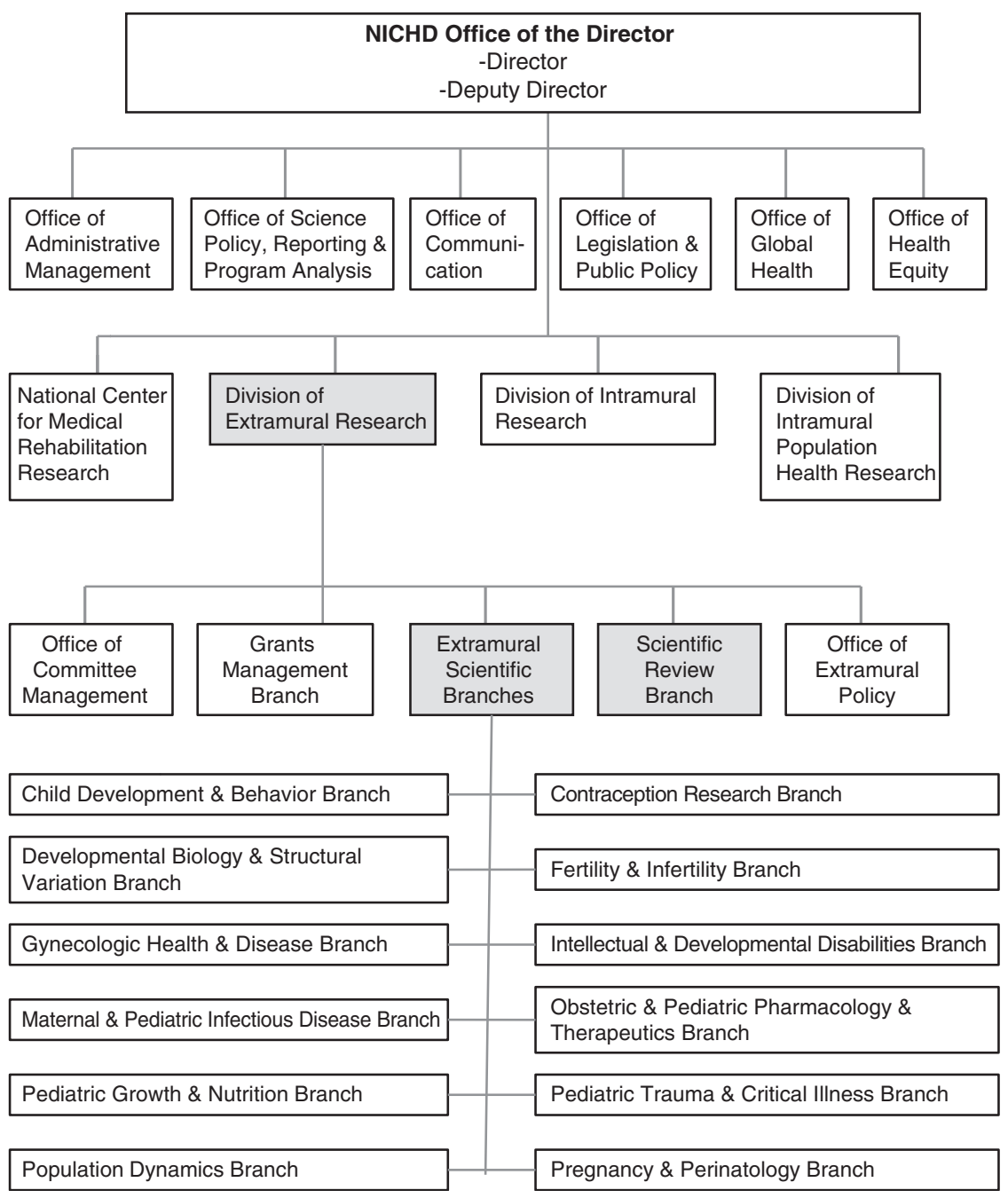

Figure 2. Organization chart of an NIH Institute (NICHD). Health Scientist Administrator positions reside within the Division of Extramural Research, where the Program Officers administer grants and contracts within an extramural scientific branch, whereas the Scientific Review Officers administer peer review of applications and contract proposals assigned to all extramural scientific branches of the NICHD for funding consideration.

the scope of the project that was proposed. Grantees also may seek advice on strategies for their competing renewals, changes in project goals, and other issues that arise in the course of a four- to five-year grant award. However, responsibility for oversight goes well beyond the individual grantees in a program portfolio. POs must stay abreast of the latest advances in their area of science by attending conferences, meeting with grantees, and reading relevant journals. These activities in turn enable POs to perform a crucial part of their job, which is to identify emerging opportunities.

\section{Scientific Review Officer}

At some time in their careers, many researchers will avail themselves of various funding opportunities provided by the NIH. The SRO bears the critical responsibility for ensuring that the 
NIH peer review process, which determines the merit of research and training applications for funding, is conducted fairly, expertly, and in accordance with NIH policy. SROs may administer the initial peer review of applications for a broad spectrum of funding mechanisms, including research grants, training grants, contracts, cooperative agreements, fellowships, and many other complex and large mechanisms. This is a sizable operation at the NIH, involving hundreds of SROs and tens of thousands of applications and proposals each year. Peer review at NIH may be conducted either in the CSR or in an institute review locus (some but not all ICs have a review branch or office). The CSR is NIH's central review organization that receives and reviews most of the "investigator-initiated" research projects, that is, those that represent investigators' own research ideas. Applications reviewed in the CSR are assigned to one of more than 100 study sections, based on the scientific match between the project and the study section's expertise, regardless of which IC will have ultimate funding responsibility. Many of the grant applications reviewed by the CSR may be of interest to several $\mathrm{NIH}$ institutes for funding. Projects that are very closely aligned with the scientific "mission" of a single IC, or are submitted in response to an IC-specific initiative, generally will be reviewed by that institute's internal review branch or office. These include large complex projects, training grants, research and development (R\&D) contracts, and career development awards. Nevertheless, whether a project is reviewed in the CSR or an IC review branch, adherence to NIH peer review policies is rigorously maintained.

\section{Organizing and Overseeing Peer Review}

The peer review process at the NIH initially involves a formal evaluation of the scientific merit of the researchers' applications, as judged by a panel of experts in the field(s) involved. A major responsibility of the SRO is to carefully assess the expertise needed to provide an informed and unbiased review of each application and to recruit persons with the appropriate expertise for formal deliberations, so that the initial review proceedings can be used by POs to identify those applications most worthy of funding. SROs recruit scientific experts from academic institutions, the private sector, and specialized groups, such as community/public representatives, when required. Notably, the SRO must avoid conflicts of interest between the investigators (and their institutions) seeking funds and the reviewers assessing the merit of their applications and proposals, while striving for balanced geographic, gender, and ethnic/racial representation on study sections to achieve a fair merit review process, free from outside influences.

Once the initial review is completed the SRO has the important responsibility to provide feedback to applicants and POs. This includes, at a minimum, the composite numerical score reflecting each reviewer's assessment of the overall scientific/technical merit of an application or other recommendation as well as a formal report of the review, called the summary statement. This document provides essentially unedited critiques from the individual experts who review the application, a "resume and summary of discussion" for applications in the top tier of those applications considered by the panel of reviewers, and other panel recommendations, such as the appropriate budget and duration of award. The SRO assures that all applicants receive this important document as a timely and accurate report of the review panel outcome, with a roster of panel members attached. The summary statement also is provided to each IC's advisory board or council for a second level of review that may include consideration of applicant concerns regarding the integrity and accuracy of the initial review. Applicants who believe that the initial peer review of their application was flawed may appeal the outcome to the council, and when this occurs, the SRO will be involved, conferring with the $\mathrm{PO}$ and providing additional information to the advisory council regarding the initial review process.

Although oversight of the initial peer review process is the heart of the duties of an SRO, and this is a sizable responsibility, it is by no means the job in its entirety. There are many opportu- 
nities for SROs to be involved in a multitude of exciting and career-building activities.

\section{Contributing to New NIH Policies}

SROs have opportunities to contribute to the development of new policies governing peer review in an ongoing effort to best serve the mission of the NIH. For example, beginning in 2009 , many procedures that prevailed for more than 50 years were overhauled in an NIH-wide movement called "Enhancing Peer Review." SROs still provide feedback on how various facets of this massive overhaul are faring in a "Continuous Review of Peer Review" mandate that invites feedback from applicants, SROs, POs, and peer reviewers for an indefinite period.

\section{Teaming with Other Government Agencies}

The NIH, as a government agency, has a timehonored system for extramural administration of biomedical and behavioral science; and partnering between the NIH and other governmental agencies is increasingly common and attests to the importance of embracing the growing emphasis on interdisciplinary science. One example was initiated by the $\mathrm{NIH}$ and the U.S. Agency for International Development (USAID), with assistance from the National Academy of Sciences (NAS). The "PEER (Partnerships for the Enhanced Engagement in Research) Health" program seeks to improve rates of child survival in low- and middleincome countries by developing interventions that reduce under-five mortality. The initial review for this program was conducted in two stages: A "preproposal concept" application was reviewed by the NAS followed by a formal initial peer review of full grant applications of the top-tier selected preproposals conducted by SROs in the NICHD/NIH Scientific Review Branch according to NIH peer review policies.

\section{Participating in and Organizing Workshops}

Joint workshops are often held by POs and SROs to provide an understanding glimpse of the NIH extramural granting process to prospective applicants. A "mock peer review meeting" is a common activity one might encounter at a scientific meeting in a workshop designed for new investigators. In addition, participating in videos of "mock study sections," webinars between NIH staff and prospective researchers for new funding initiatives, and web-based training for the scientific community are increasingly commonplace functions for SROs and POs at the NIH.

\section{Designing and/or Testing New Technologies}

As an alternative to in-person meetings of reviewers, which has traditionally been the gold standard for NIH peer review, the NIH is developing and continuously improving several "platforms" for the conduct of initial peer review. These are evolving at an impressive speed but always with the intent of providing a fair and optimal venue for the peer review process. In addition to novel review meeting strategies and accompanying technology development, new software is continuously under design and trial, often initiated and tested by creative SROs.

\section{Participating in Training Opportunities}

Requests from foreign institutions and scientific societies present opportunities for workshops with SROs that often lead to publications of workshop proceedings and/or white papers.

\section{Congressional Inquiries}

SROs may partner with other NIH staff, such as POs, to address congressional inquiries in response to requests from constituencies, seeking clarification for funding of certain projects, outcomes of peer review, or other issues.

\section{SKILLS AND QUALIFICATIONS}

Most Science Administrators at the NIH are expected to have a doctorate-level degree, such as a $\mathrm{PhD}$, and many have combined degrees; for example, $\mathrm{PhD} / \mathrm{JD}, \mathrm{MD} / \mathrm{PhD}, \mathrm{PhD} / \mathrm{DVM}, \mathrm{DDS} /$ $\mathrm{PhD}$, or $\mathrm{PhD} / \mathrm{MPH}$. Many seek this position 
after a career as an independent research scientist, although some enter the profession immediately following postdoctoral training. There appears to be a growing number of investigators not long out of postdoctoral training that are now seeking administrative jobs in science as their first choice of career. Either way, most scientists have developed numerous skills that are essential not only for being a successful researcher or teacher, but also for being an administrator. The most important qualification for the job is a love and appreciation of good science; that is why POs and SROs are officially called scientist administrators. One also needs excellent organizational skills, a talent for verbal and written communication, the ability to work well with others as a team, a capability for multitasking, and good common sense. There are many training opportunities to hone existing skills and to acquire on-the-job training.

Two key questions when considering a new career are the following: (1) What are the rewards? and (2) Is this career a good fit for you and your skills and talents? If you are interested in becoming a PO, will you enjoy the "social worker" part of the job-the gratification that comes from helping applicants and granteesor will you dread speaking with disappointed grant applicants? Will you enjoy being at the forefront of science where one gets a broad overview of how areas connect and evolve over time, or will you miss the opportunity to drill down into the details of a specific problem? Although it is more important than ever to be able to guide and advise grantees at a time of tight budgets, it also means that difficult and unpopular funding decisions have to be made. Over the longer term, if you think it would be great fun to learn new areas of science and watch them morph, driven in large part by the scientific community, but also with a little help from you and the NIH, a PO may be a good career to consider.

For an SRO, there are additional rewards and challenges worth mentioning. One reward, which also is a challenge, is to oversee, in a neutral and unbiased manner, the peer review of projects similar to the research that you previously performed, without inserting yourself into the review of an area with which you are very familiar.

\section{GETTING A FOOT IN THE DOOR}

Program and review jobs are constantly turning over at the NIH. Specific jobs are posted on www.usajobs.gov and a global job registry periodically accepts resumes from individuals interested in scientist administrator positions. When someone at the NIH is interested in hiring a science administrator, they often search the global registry for promising candidates before posting a job announcement to the community via society and journal advertisements. A good way to start a search for a scientist administrator job is to contact a PO or SRO with whom you or your mentors have had previous interactions.

A strong publication record may be useful, but it is not necessary-note that some enter this arena directly from a postdoctoral position. Perhaps more advantageous is the demonstration of the skills and qualifications described previously; for example, excellent organizational skills, a talent for verbal and written communication, and the ability to work effectively in a team.

To demonstrate these broader talents, consider becoming involved in student organizations, organizing academic events, or taking advantage of writing opportunities ( particularly related to science and technology). Then, ensure that your resume reflects the administrative/ organizational and communication skills that you have developed.

\section{CAREER PROGRESSION}

Whether you opt for a position as a PO or SRO, the career paths for an HSA are certainly not dead-ended. The ability to keep abreast of cutting-edge science and make a significant impact is there for both types of administrators, as is the ample opportunity for lateral movement back and forth in a vast number of organizational settings within the federal workplace (Fig. 2).

Once one enters an administrative career at the NIH as a junior- or mid-level scientist, there are many pathways to follow and many oppor- 
M. Zatz and S. Dupere

\section{BOX 1. Our Experience}

\section{Marion's Story}

I began my research career as an academic research immunologist and Clinical Director of a tissue transplantation laboratory. After a hiatus in my career during which I raised two young children, I returned to a full-time academic research position but soon discovered that I was ready for new opportunities and challenges. After speaking with the PO for my own NIH research grant, I realized that research administration could provide the opportunity to approach science from a broader perspective and to develop my "social worker" side. Service to the scientific community, coupled with a continuing connection to science, seemed like an ideal direction to pursue.

As a PO at the NIGMS for more than 27 years, I have seen many swings of the NIH budget pendulum - from the 1990 budget crisis, to the 1998-2003 budget doubling, to the current fiscal situation. I have also witnessed the evolution of science overall because the areas for which I had responsibility continuously changed. My first PO job at the NIGMS involved developing a new program in molecular immunobiology that built on my previous immunology background, as well as assuming responsibility for a program in cell growth and differentiation, an area about which I knew little. Over time, the program area in cell growth and differentiation grew to include the rapidly emerging area of cell cycle control. Later, the area of programmed cell death blossomed and became a new focus for my program responsibilities. The most recent evolution of my program came to encompass the exciting new area of basic stem cell research. Clearly, while remaining at the NIGMS for many years, the nature of the science that I administered was constantly changing, as were my other activities.

Although my initial role as PO focused on administration of research grants, I acquired new responsibilities for administering training support mechanisms, such as individual postdoctoral fellowships and institutional predoctoral training grants. Training strategies must keep pace with workforce needs as well as the increasingly more complex and multidisciplinary practice of science. I have had the opportunity to develop new PhD training grant programs in two emerging areas: bioinformatics and computational biology, and molecular medicine. Equally important has been the challenge of promoting diversity in the biomedical and behavioral workforce. I have been involved in many activities over the years with this goal in mind, including organizing a workshop for training grant program directors, "Achieving Scientific Excellence Through Diversity," developing a new NIGMS website for diversity recruitment and retention strategies, and serving on the NIGMS Committee for Biomedical Workforce Diversity. My current responsibilities are to manage NIGMS diversity and reentry supplements programs that provide supplemental funds to research grants to recruit and train underrepresented individuals, from high school students through postdoctoral fellows, with the goal of increasing the diversity of the biomedical and behavioral workforce.

Although I never expected to become a science administrator when I entered graduate school, and never even knew that such a job existed, I clearly discovered a career that blends my love of science with the rewards of serving the research community. In 2012, I retired from my position as PO and from the federal government, but I have been fortunate enough to be able to continue some of my professional activities as a part-time contractor overseeing the NIGMS diversity and re-entry supplement programs. This has been a career that keeps on giving!

\section{Sherry's Story}

I financed my undergraduate education leading to a BS in zoology/microbiology through full- or part-time employment in clinical laboratories (as a technician in a university endocrine-metabolism research laboratory and subsequently as head of a serology laboratory in a large mid-western hospital). After gaining accreditation of the serology laboratory as a state reference laboratory, I returned to graduate school and earned an MS in cell biology, followed by a PhD in immunology. I acquired my initial postdoctoral training in a national laboratory with research on chromatin neoantigens in

(Continued) 
carcinogenesis. A second postdoctoral stint at a large cancer center was spent specifically conducting research on proto-oncogenes and oncogenes in "viral carcinogenesis," and I was finally involved in phase I-II clinical trials of rH-tumor necrosis factor at this cancer center on a contract with a Japanese pharmaceutical company.

Eventually I joined the NIH as "Microbiologist" at the National Institute of Allergy and Infectious Diseases (NIAID), Division of Extramural Activities, where I functioned as an SRO heavily involved in the administration of peer review for grant and cooperative agreement applications and contract proposals related to HIV/AIDS. From there, I became Review Officer at the Fogarty International Center/NIH for initial review of research and research training grant applications in international biodiversity, international HIV/AIDS epidemiology training, and international bioethics training, among others.

After a subsequent move to the NIH Center for Scientific Review, I initially administered a federally chartered review panel ("study section") that availed of my previous research in proto-oncogenes in development and cancer, plus molecular and genetic aspects of development, cancer, and aging. At the CSR, I rose through the ranks to the position of Chief, Biology of Development and Aging Integrated Review Group (IRG). In this role, I helped to create and administer a group of study sections that still exist and have served many of the NIH ICs, including the NIGMS, and my coauthor Dr. Marion Zatz, whose portfolio consisted in part of applications that underwent peer review in some of my study sections. One of the most gratifying of my SRO duties at the CSR was in serving as a member of the NIH Stem Cell Implementation Committee, at a time when the topic of regenerative medicine/ stem cells began to emerge as an integrated $\mathrm{NIH}$-wide effort (due largely to the efforts of HSAs such as Marion Zatz as a PO, heavily involved in projects involving stem cells).

In 2010, I was honored to join the Eunice Kennedy Shriver National Institute of Child Health and Human Development (NICHD) as Chief, Scientific Review Branch. The NICHD celebrated its 50th anniversary in 2012, and for me, the main attraction for joining this IC was (and remains) its mission: "to ensure that every person is born healthy and wanted, that women suffer no harmful effects from reproductive processes, and that all children have the chance to achieve their full potential for healthy and productive lives, free from disease or disability, and to ensure the health, productivity, independence, and well-being of all people through optimal rehabilitation." With a mission of such breadth, the opportunities for making a meaningful contribution are immense for anyone seeking a career in biomedical and behavioral research administration and training.

In summary, my 23 years at NIH have consisted of the administration of initial peer review in four institutes/centers. Looking back over two decades, I have not regretted the move to the $\mathrm{NIH}$ as an HSA at any stage; this remains a challenging and dynamic position that I heartily recommend to anyone seeking a meaningful and rewarding science career.

tunities for upward mobility. Within the career track of a scientist administrator, it is not uncommon to switch from being an SRO to a PO or vice versa, to move from one IC to another, or move to a policy position within the central NIH Office of the Director, often with responsibility for broader areas of science and supervision of personnel. In addition, armed with the skills and knowledge of a PO or SRO, many more senior scientist administrators move into administrative positions of leadership and responsibility in other funding agencies and organizations, academic institutions, or professional societies. Scientist administrators should expect to have highly rewarding careers that build on their training, knowledge, and identity as a scientist.

\section{WAY OUT}

Taking a position as a scientist administrator does not have to be a one-way street; however, the longer you are in an administrative position, the harder it is to resume a research career. Therefore, scientists who make this transition should be ready to leave bench research and move on to the rewards of a new career in science. In moving out of a position of science administration, con- 
M. Zatz and S. Dupere

\section{BOX 2. Ten Dos and Don'ts}

1. Do not view a position as an administrator as a dead end. There are many opportunities for administrators in academia, government, and private industry.

2. Do be ready to leave the bench.

3. Do focus on how you can use your training to further science in a new way.

4. Do speak to people in administrative positions and colleagues who have interacted with NIH scientist administrators.

5. Do develop a resume that highlights the administrative and science skills that you have developed.

6. Do develop a sense of whether you would prefer serving as an SRO, PO, or a policy official.

7. But do not disregard the possibilities of moving among SRO, PO, and policy officer positions as you contemplate the HSA career route for long-term growth prospects within the NIH.

8. As you progress in your career, do keep up with current events in scientific areas relevant to your field(s) of interest and training; the HSA is a scientist in his/her own right.

9. Do focus on how you can work cooperatively with all factions in order to allow the best science to move forward.

10. Do not forget to explore the value of formally "mentoring" through sharing the wisdom of your life experiences and thereby filling the "brain drain" as more senior HSAs leave the workforce.

sider the many opportunities that exist elsewhere in the government, in universities, and in the private sector that require the skills and abilities that you have developed.

Within the government, it is possible to move within or between federal agencies to gain experience and take on new leadership roles in other areas of administration or in policy. Similarly-outside of the governmentpharmaceutical and biotech companies, nonprofits, and private foundations all offer many positions well-suited for government adminis- tration professionals. Finally, universities and other research institutes typically sponsor research programs or other projects that may require grant specialists or program managers or those capable of communicating science to a broader audience. Any of these careers may be a good fit for some individuals with experience in science administration.

\section{WWW RESOURCE}

usajobs.gov A global job registry. 


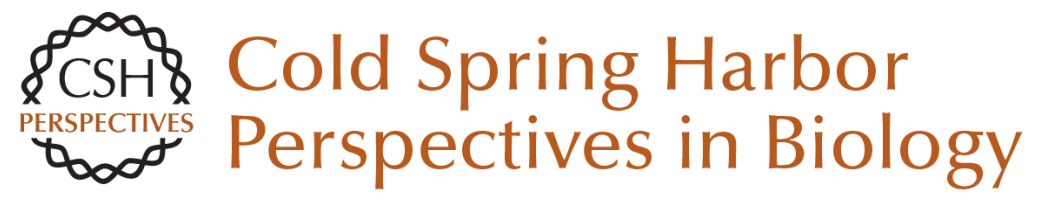

\title{
Careers in Science and Grant Administration: View from the National Institutes of Health
}

\author{
Marion Zatz and Sherry Dupere
}

Cold Spring Harb Perspect Biol 2018; doi: 10.1101/cshperspect.a032847

\section{Subject Collection Career Options for Biomedical Scientists}

\section{Careers in Science Publishing} John R. Inglis

Medical Communications: The "Write" Career

Path for You?

Yfke Hager

At the Crossroads of Science and Society:

Careers in Science Policy

Amy P. Patterson, Mary E. Groesch, Allan C. Shipp, et al.

A Career in Patent Law: At the Cutting Edge of Science, but Not at the Bench Salim Mamajiwalla

Careers in Science and Grant Administration:

View from the National Institutes of Health Marion Zatz and Sherry Dupere

Careers at Biotech Start-Ups and in

Entrepreneurship

Susan Froshauer

Careers in Science Journalism and Writing Helen Pearson
Careers in Academic Administration Lydia Villa-Komaroff

Working for a Scientific Society Martin Frank

\author{
A Career for Life Scientists in Management \\ Consulting \\ Rodney W. Zemmel \\ Careers in Core Facility Management \\ Claire M. Brown \\ Leaving the Bench and Finding Your Foundation \\ John E. Spiro \\ A Career at a Small Liberal Arts College \\ Jennifer Punt \\ Career Options for Scientists \\ Richard Sever and Kaaren Janssen
}

For additional articles in this collection, see http://cshperspectives.cshlp.org/cgi/collection/

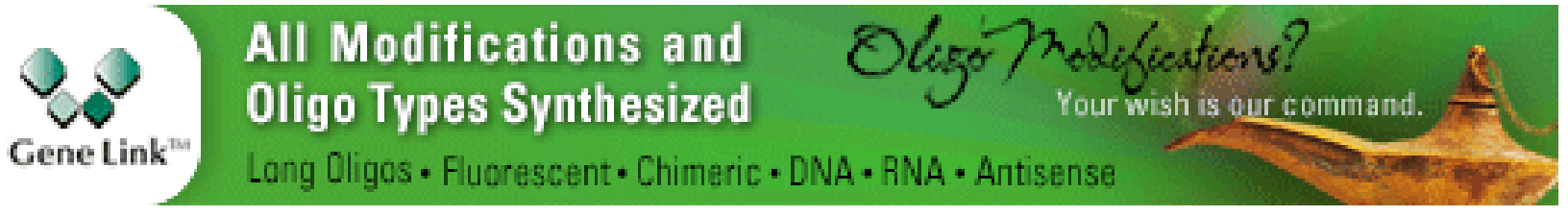

Copyright @ 2018 Cold Spring Harbor Laboratory Press; all rights reserved 